\title{
A Study in the Flow of Financial Resources in the Yangtze River Delta from the Perspective of Financial Gradation Cities in Urban Agglomerations
}

\author{
Mingzhu Li ${ }^{1}$, Rongxin $\mathrm{Xu}^{2}$, Di Zhou ${ }^{3, *}$ \\ ${ }^{1}$ School of Public Administration, Guangdong University of Foreign Studies, Guangzhou, China \\ ${ }^{2}$ School of Economics and Trade, Guangdong University of Foreign Studies, Guangzhou, China \\ ${ }^{3}$ School of Mathematics and Statistics, Guangdong University of Foreign Studies, Guangzhou, China \\ Email address: \\ limingzhushe@126.com (Mingzhu Li), 15889137927@163.com (Rongxin Xu), zhoudi19880101@163.com (Di Zhou) \\ ${ }^{*}$ Corresponding author
}

\section{To cite this article:}

Mingzhu Li, Rongxin Xu, Di Zhou. A Study in the Flow of Financial Resources in the Yangtze River Delta from the Perspective of Financial Gradation Cities in Urban Agglomerations. Earth Sciences. Vol. 8, No. 3, 2019, pp. 205-216. doi: 10.11648/j.earth.20190803.18

Received: May 31, 2019; Accepted: July 1, 2019; Published: July 17, 2019

\begin{abstract}
The barrier-free flow of financial resources among nodes (regions) is not only conducive to more efficient use of financial resources, but also plays an important role in alleviating the contradiction between supply and demand of regional financial resources and promoting regional economic development. Based on the theory of spatial interaction among financial gradation cities, the paper takes the expansion of commercial banks in the Yangtze River Delta as an example, and constructs the flow network of financial resources between cities. Using the social network analysis (SNA) and Dagum Gini coefficient decomposition method, the paper analyzes a series of problems such as the development of the financial resources, flow path selection and flow coordination during the period 2008- 2014. The conclusions can be drawn as follows: (i) the flow density between prefecture-level cities is the largest, which grows rapidly as time goes by, followed by county-level cities to prefecture-level cities and the flow density between other sorts of cities is relatively small. (ii) The flows of financial resources between prefecture-level cities presents typical features of homogeneous diffusion, while the flows from prefecture-level cities to counties and other sorts of cities has the feature of conditional diffusion. Flow barriers between provincial level border holds the biggest effect, followed by the differences of economic and financial development level between the prefecture- level cities and county- level cities. Among the effects of condition, Provincial-level borders have the greatest impact, followed by urban economic gaps and financial development gaps. (iii) The degree of variance in financial resource inflows within county-level cities is the largest, and the inflow of financial resources in country-level cities has a tendency of Matthew effect. It shows that in the Yangtze River Delta, the trend of integration only exists between prefecture-level central cities. Moreover, the radiation effect of central cities on its financial hinterlands is not strong which should be further strengthened. Therefore, on the one hand, the integration policy at macro-level such as "regional financial coordination policy" and "regional trust system construction" in the urban agglomeration of this region should cover the country-level cities. On the other hand, country-level cities themselves (especially the backward countries) should also make great efforts to improving the current economic and financial environment by narrowing the gap between the cities to reach the goal of Planting Phoenix trees well to attract Phoenix.
\end{abstract}

Keywords: Financial Gradation Cities, Urban Agglomerations, Financial Resources Flow Network, Flow Coordination, Flow Density, The Yangtze River Delta

\section{Introduction}

With the importance attached by government on regional planning and the improvement of transportation infrastructure, the economic integration of urban agglomerations in the Yangtze River Delta grows at an ever-accelerating rate. However, compared with economic integration, the extent of financial cooperation in the Yangtze River Delta is so far very limited. Pronounced geographical characteristics exist in 
business management system of banking institutions, and business activity conducted by the bank branches are restricted in specific administrative area [1]. At present, there are 1 municipality, 15 prefecture-level cities, 32 county-level cities and 21 counties in the core urban agglomeration of the Yangtze River Delta, among which the ratio of loan and deposit balances of financial institution at the end of 2013 differed to a considerable extent. e.g., Shanghai is 0.641 , the average values of prefecture-level city, county-level cities and counties in Jiangsu province were $0.730,0.714$, and 0.663 , while the average values of the three level in Zhejiang province are 0.864 , 0.863 , and 0.938 respectively. This indicates that cities (especially county-level cities) in Zhejiang Province have obvious funding needs, followed by cities in Jiangsu Province, while in Shanghai funds are more sufficient. The existing discrepancies also prove that Shanghai does not provide effective financial support for regions such as Zhejiang and Jiangsu. It can also be seen from above that the flows of financial capital within the Yangzi river delta is insufficient.

What is the current regional mobility of financial resources in the Yangtze River Delta? What are the affecting factors of regional mobility? What are the differences in the flows of financial resources between different types of cities? The discussion of these issues is not only conducive to the more efficient use of financial resources, but also important for improving the contradiction between supply and demand of financial resources in the Yangtze River Delta and promoting the overall coordinated development of economic and financial resources in the Yangtze River Delta region.

Abundant achievements in the study of the flow of financial resources have been made by domestic and foreign scholars. The study object of foreign scholars are more of different economies, such as analyzing the degree of financial capital and assets in different countries or regions (degree of financial integration). Research methods they come up with mainly include price method and quantitative metho [2-11]. The price method is based on the interest rate parity theory. e.g., Cheung et al. used this method to test the capital flows of China, Hong Kong, and Taiwan, and found evidence of capital flow [4]. Yu et al. use different high-frequency data indicators to examine the degree of integration between stock markets in East Asian countries [6]; While in quantity method, Feldstein et al. proposed the famous FH method to measure regional capital mobility by examining the degree of correlation between investment and savings in different countries. It comes out that the higher correlation between the savings rate and investment rate suggests the lower degree of capital flow of a country [7]. Drawing on this idea, Le examines 15 Asia-Pacific economies and finds that coefficient of average savings-investment is 0.73 , indicating that regional capital flows are limited [8]. Kim et al. also indicated that although the correlation coefficient of savings-investment in East Asian countries has been decreasing over time, it is still higher than that of OECD countries, and the capital flows in East Asian countries are still relatively low [10]. However, since pro-cyclical characteristic exists between savings and investment, there is often a high correlation coefficient between the two [6]. Domestic scholars are more concerned with the study of the structure and causes of financial resource flow within a country. Network analysis method is the most commonly used method in their researches and the construction of the network is achieved by gravity model or based on the actual relationship of financial resource. E.g., Hou Yundi et al. constructed a capital flow network for 25 central cities in the Yangtze River Delta through gravity model, and explored the spatial structure of different cities by means of social network analysis (SNA) [12]. Hu Kai measured the scale and causes of China's capital flows from the provincial level according to the basic theory that the flow of goods and services are in opposite direction.

Based on the review of these literatures, the paper finds the insufficiency about recent research: (i) judging from research object, the research on the regional flow of financial resources is mainly from a limited level of financial funds and capital, taking insufficient account of financial resources like financial institutions. In fact, financial resources include three levels: monetary assets (funds), financial organization systems and financial instruments, and the overall function of the financial system [14]. For the second-level, Ji Feifei et al. made the first attempt to measure the flow of financial resources by the expansion of financial institutions, and visualized the flow of financial resources among different cities through data visualization, analyzing the status of cities in the entire financial mobile network, as well as the mechanism of mobility [15]. However, it is based on 25 cities in the Yangtze River Delta urban agglomeration, ignoring the perspective of the spatial role of financial cities, and therefore not yet unearthed the characteristics of financial flows between different financial gradation cities. (ii) In terms of research method, it is more effective to construct the network when studying the distribution pattern of resources and the flow of resources. However, in existing researches, the construction of network is limited to the analysis of material flow, information flow, population flow and comprehensive economic flow [16-20]. Besides, gravity model is commonly used to construct the network [18, 20-22] which is in fact insufficient to reflect the flow of resources, as it is only a simulation of connection rather than real one.

In this paper, based on the theory of financial gradation cities, we starts the research of the flow of financial resources from prefecture-level cities, county-level cities, and counties. In addition to studying the density and flow path of financial resources between cities, we also examine the coordination of financial resource flows using the data on the discrepancies in financial resources inflows among various types of cities to make the research further and the conclusions and recommendations more targeted.

\section{Theoretical Framework and Study Method}

\subsection{Theoretical Framework}

\subsubsection{Theory of the Financial Resources Flow in Financial Gradation Cities in Urban Agglomerations}

Financial efficiency presents the distribution of overall 
financial sector within a specific time and space [23], and Pareto improvement in financial efficiency serve an endogenous mechanism of the regional movement of financial sector. As a part of the financial sector, commercial banks in Yangtze River Delta match the theory of Pareto improvement in financial efficiency when referring to their expansion to different areas: On the one hand, financial institutions can improve their efficiency through economies of scale if they can operate their business and allocate resources in a wider range. On the other hand, they can also promote the economic and financial development when financial resources flows into a city.

According to the differences in the growth stages of the financial industry in different cities, financial gradation cities can be roughly divided into three types: financial fulcrum, financial growth pole and financial center (Figure 1). The financial industry of financial fulcrum cities are at the low-level of its growth stage with small financial scale and weak intensity. The financial industry of financial growth poles obtains the growth of a certain extent, occupying a larger share in the industrial structure and becoming a pillar industry. In financial center cities, the level, scale and intensity of urban financial functions have reached a certain height, and the financial industry has leapt to hold a commanding lead, taking the lead in the industrial structure system, and largely determining the future development direction and development patterns of the industrial structure [23]. There are many cities in an urban agglomeration, and under the most common situation, its spatial layout, with very few financial centers surrounded by a large number of financial growth poles and financial fulcrums is shown in Figure 1.

Because there is a systematic difference in the demand for financial services in the real economy at different stages of economic development [24], the financial industry cannot develop in isolation from the carrying capacity of regional economic development, and its powerful functions such permeability, independence and orientation rests upon the regional economy. We assume that the types of financial gradation cities are consistent with the levels of cities, i.e., the city-level, county-level cities and counties respectively correspond to financial centers, financial growth poles and financial fulcrums. It is an appropriate and innovative attempt to analyze the flow of financial resources between different levels of cities in the Yangtze River Delta draws upon the theory of financial resources flow in financial gradation cities.

In the cluster mode, a constant exchange of material, energy and information exist among cities, which is called the spatial effect of cities. Haggett divides the spatial interaction into three types: convection, conduction and radiation [25], which we use to link up with the movement of goods and population, the financial and financial exchanges, and the flow of information in reality when referring to the connections between cities, and therefore can be used to discuss the spatial economic system of urban agglomeration in the Yangtze River Delta [20]. The Ullman system describes three conditions for spatial interaction: complementarity, media opportunity, and transferability [26]. The geographical flow of financial resources in urban agglomeration mainly comes from the correlation effect of financial industry between different financial cities, in which there are two spatial functions_- polarization effect and diffusion effect. Besides, polarization effect and diffusion effect of financial industry mentioned above are only abstract functions that needs to be achieved through specific geographical movements in reality. Specifically, the law of motion of financial gradation cities can be explained using Figure 2:

(1) There is a weak correlation between the financial fulcrum and its external environment.

Because the financial transaction subject of the financial fulcrum cities is not strong in trading motive, the financial industry is limited in scale and is restricted to their own capital accumulation. The counties in the urban agglomeration of the Yangtze River Delta are cities of this type with limited financial resources, and therefore have relatively narrow geographical influence, among which exist only a limited attraction to surrounding villages and limited interactions with other financial fulcrums, financial growth poles and financial centers. E.g., (g) and (i) in Figure 2, is in a typical situation where there is no connection the financial fulcrum with surrounding cities.

(2) For financial growths, the agglomeration effect and the diffusion effect play a synchronous role, but their effects are limited.

The specific performance is as follow: First, broadly attract financial resources from surrounding areas; second, radiate and promote the development of other financial fulcrums; third, it can also transfer and replace financial resources with other financial growth poles. E.g., from one side the financial growth pole (d) in Figure 2 is under the influence of radiation surrounding financial center (a), from another side, the agglomeration and diffusion effect of the financial fulcrum (j) and only a diffusion effect on (h). However, the limited scale and strength of its financial function and the lower level of financial functions of financial growths make it insufficient in diffusion effect so that in the figure, the diffusion linkages are relatively.

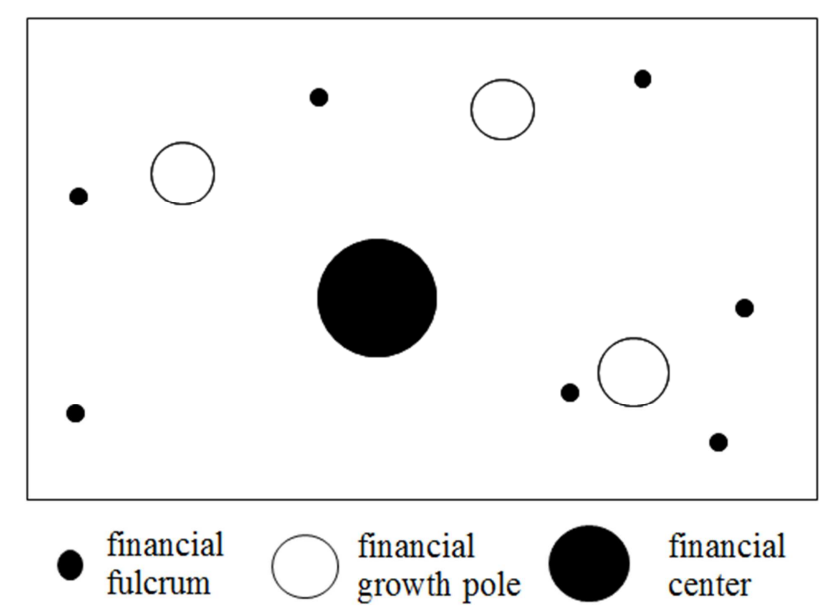

Figure 1. Spatial movement of financial gradation cities. 

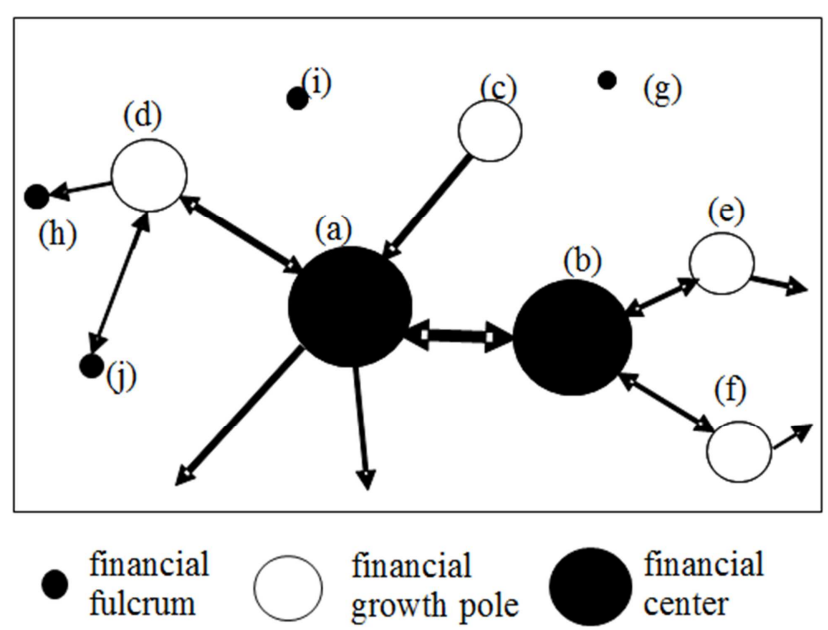

Figure 2. Financial gradation in urban agglomeration.

(3) The financial center has a strong spatial diffusion effect. Strong external connection exist in financial industry of financial centers especially in their diffusion effect. The reason is that the financial resources agglomerated in a region are limited, therefore, when the financial resources exceed a certain level and go on to aggregate, the cost of the financial industry will rise, resulting in diseconomy of agglomeration. The specific performance is as follow: first, they transmit resources and promote development of other financial growth poles and financial fulcrums; second, they transfer and replace financial resources with other financial centers. E.g., (a) and (b) in Figure 2 both have radiation effects on financial growths around. Transmission and replacement of financial resources also exist among them.

Based on the law of motion of financial gradation cities, We will analyze that to what extent the flow characteristics of financial resources between different levels of cities in the urban agglomeration of Yangtze River Delta is in line with situation above later.

\subsubsection{Path Selection Mechanism of Financial Resource Flows}

As a geographical phenomenon about spatial movement, the spatial diffusion of the financial industry shows up as the spatial transfer and dissemination of financial industry from the source region or the core area with high "potential energy" to the outside. The path selection of spatial diffusion is an important issue of space movement: Hagerstrand proposed three basic types of spatial diffusion: contagious diffusion, hierarchical diffusion, and relocation diffusion [27] $\mathrm{Lu}$ Jun argued that the basic modes of spatial diffusion are homogeneous diffusion (or neighborhood diffusion) and conditional diffusion (or non-neighborhood diffusion). To the homogeneous diffusion, the diffusion behavior are characterized by random spatial propagation to the outside of the domain without specific spatial directivity, while to the conditional diffusion, special requirements of the destination exist in its diffusion process, which shows obvious spatial directivity characteristics [28].

Base on previous researches, we suggest that there are several factors determine the expansion path choices of financial resources (especially the commercial banks). 1) The level of financial development. The flow of financial resources stems from the differentiation of financial resources within the region [29]. For financial institutions, the higher the per capita deposits and loans of a region, the greater the scale of its business, and the further it promotes its own development, therefore, institutions are often more willing to have branches in cities with higher levels of financial development. In addition, financial interrelations ratio (FIR) is a financial indicators commonly used to measure the financial development level in a region. 2) The factors of globalization. Under the background of globalization, some cities with better economic bases and prevailing location conditions establish a dominance in financial agglomerations, which are more likely to become financial centers. Through the radiation of financial centers, financial growth poles and financial fulcrum cities will continue to emerge, rushing the spatial movement of financial gradation cities. In addition, the global flow of financial resources is accelerating because of globalization, promoting regional financial diversification, and strengthening linkages between different countries and regions [30]. 3) The level of marketization. With high levels of marketization, intervention in financial institutions is less so that economy is more dynamic, which is more conducive to the development of financial institutions. 4) The level of economic development. Economic level is the basis of financial development and finance and economy can promote the development of each other. On the one hand, regions with high level of economy development tend to generate higher financing needs. A large number of high-quality loans are the basis of commercial banks development, showing their profitable need. On the other hand, in areas with high levels of economic development, there is often a large amount of household savings ensure a stable source of loans. 5) The level of integration. The flow of financial resources in urban agglomerations will be limited by administrative boundary effect. Under the implementation of tax-sharing policy after 1994 tax reform, local government tends to hinder the expansion of financial institutions for two reasons. One reason is that under the current central and local tax sharing system, the allocation of tax administrative power on corporate income tax lies on the regional subordination relations between enterprise and government. Under this situation, local governments tend to control and intervene in order to increase its tax revenue, which puts a negative impact on the rational flow of production factors and on cross-border business operations as well as asset restructuring. On the other hand, local government's financial resources run into a distinct decline caused by the 1994 tax-sharing reform, resulting in a tighter control over finance sector to prevent the loss of financial resources from local aspect [31].

\subsection{Bank Selection and Data Sources}

At present, there are 15 city commercial banks in the 16 
core cities of the Yangtze River Delta. In our study Ningbo Tongshang Bank and Ningbo Donghai Bank are excluded because of their relatively shorter establishing time span. Therefore, we choose 13 other banks, which include Shanghai-based Bank of Shanghai, Jiangsu based Bank of Nanjing, Bank of Suzhou, Bank of Jiangsu and Jiangsu Changjiang Commercial Bank, Zhejiang based Bank of Hangzhou, Bank of Jiaxing, Bank of Taizhou, Bank of Ningbo, Bank of Huzhou, Bank of Shaoxing, Zhejiang Mintai Commercial Bank, Zhejiang Tailong Commercial Bank as our research object. Using these data, we carried out a statistical analysis base on the time and quantity of the headquarters and branches of these banks in other cities in the Yangtze River Delta region, regarding the banks' establishment of branches in different places as a form of financial resources.

The administrative divisions of cities and counties in the Yangtze River Delta region have changed with time and in this paper, we fix it in 2018, during which there is 1 municipality, 24 prefecture-level cities, 41county-level cities, and 51 counties. In addition, as a municipality, Shanghai, will be merged into prefecture-level cities in order to facilitate the analysis. At the same time, in order to avoid the data conflicts, relative statistics of countryside in prefecture-level cities are excluded.

\subsection{Research Methods}

In this paper, we use branches that city commercial banks set up in different cities to establish a financial mobility network within urban agglomerations. General statistical methods are not suitable in our analysis because the flow network data we collect is relational data, and the statistical processing of which is quite different from normal attribute data. Therefore, as a solution, in current researches, social network analysis (SNA) are commonly used in the study the flow network. In this paper, two analytical methods in SNA - Density analysis and quadratic assignment procedure (QAP) regression analysis are adopted.

The role of density analysis is to measure the inherent cohesion of the network, and the density of a network with $n$ nodes is calculated by the ratio of the number of existing connections in the network and maximum numbers of possible connections. The formula is as follows:

data caliber, the statistical caliber of the prefecture-level city is confined to urban area. The data comes from the official website of the banks and the website of Zhejiang Industry and Commerce Bureau, Jiangsu Provincial Administration for Industry and Commerce, the website of Shanghai Industry and Commerce Bureau.

$$
\mathrm{D}=\frac{e}{n(n-1)}
$$

In the formula: e represents the number of existing connections. The greater the density, the closer the relationship between the overall network members.

The commonly used software for SNA is Ucinet, but there is a requirement for data when using Ucinet to calculate density. That is, the data must be $\mathrm{N} \times \mathrm{N}$ matrix shape to calculate the density of the whole network composed of $\mathrm{N}$ nodes. However, the data we collect does not meet this standard, therefore, we manually calculated the network density between different types of cities by the density formula to cope with the data limitation. Taking the calculation of the density of prefecture-level cities flowing to county-level cities as an example, first, we calculate the number of institutions $e_{i}$ set up by prefecture-level cities $i$ in all county-level cities. Since city commercial bank headquarters only exist in eight cities in the Yangtze River Delta urban agglomeration, $\mathrm{i}$ is equal to 8 , and then we go on to aggregate the prefecture-level cities $\mathrm{e}_{\mathrm{i}}$. In addition, the maximum possible number of connections is the square of the number of the county-level cities N. A new density formula is obtained:

$$
D_{\text {prefecture-level cities } \rightarrow \text { country level cities }}=\frac{\sum e_{i}}{N^{2}}
$$

The density calculation process of mobile networks between other cities is similarly constructed as above, and will not be explained repeatedly.

The QAP method is based on resampling. By comparing and analyzing the similarity of each cell value in two 1D N $\times N$ matrices, the correlation coefficient between the two matrices can be calculated and non-parametric test of the correlation coefficient can be achieved further. The QAP method is also used for observed value with collinearity and autocorrelation, which makes it more suitable for estimating regression analysis of network data than OLS [32]. In order to make the network data being dimensionless, we use range standardization method to process the difference in network matrix data that affects the flow of financial resources, and then carries out QAP correlation analysis and QAP regression analysis on the mechanism of financial resource flow network. Comparing to the Tyre index decomposition method, there is an improvement in the Dagum Gini coefficient decomposition method because of its consideration of the distribution of sub-samples.

We make it on the basis of the various type of city levels in the decomposition process, which is different from general regional classification methods. Under this circumstance, the overall Gini coefficient is divided into three parts: the contribution of the gap within the hierarchy $\mathrm{G}_{\mathrm{w}}$, the contribution of the net difference between the levels $G_{n b}$, the contribution of the hypervariable density $\mathrm{G}_{t}$, thus, $G=G W+G n b+G t$. The specific decomposition can be referred to the relevant literatures [33].

\section{Analysis of Financial Resource Flows Between Different Financial Cities}

\subsection{The Measurement of Financial Resource Flow Network Density}

In order to look into the degree of financial resource mobility among different financial cities, this paper uses the 
"density" formula in social network analysis (SNA) to measure the density of financial resources flows between different types of cities. In addition, in order to examine the limitation of the administrative boundary effect on financial resources flow in the Yangtze River Delta, the article has subdivided the financial mobile network, and measured the networks of financial resource flows and the network density between 2012, 2014 and 2018 from the perspective of the overall network, inter-provincial network and cross-city network respectively. The number of networks are represents the number of branches set up by commercial banks and the network density is calculated by formula (2). The results are shown in Table 1 to Table 3 , and the data in the table indicates the statistical results of the financial resources flowing from cities in the vertical row to the cities in the horizontal row the end of each corresponding year. E.g., in 2018, in the overall network, the number of networks the prefecture-level city flows to the county level is 114 , and the network density is 0.1112 . In the inter-provincial and inter-city financial mobile networks, the number of networks is 15 and 100, respectively, and the network densities are 0.0156 and 0.0976 respectively.

As can be seen from Table 1, the number of financial networks among different cities is increasing over time, and the density of financial networks is increasing steadily. Furthermore, the highest density in the flow of financial resources among which is from prefecture-level to prefecture-level cities, followed by county-level cities to prefecture-level cities county-level cities, while county-level cities to county-level cities have the lowest level of financial resources.

Through observation of the unprocessed data, it can be found that a large number of inter-city financial resource flows occur within the same province that suggest an obvious provincial boundary effect. For example, in 2018, all of the new branches set up by Zhejiang Province based Bank of Jiaxing, Bank of Shaoxing and Bank of Huzhou, which are 55, 76 and 30 respectively, locates in Zhejiang entirely.

In Table 2, the resource flows between cities within the same province are excluded, only the inter-provincial financial resource flow network is reserved, and we can infer that: 1) For the prefecture-level city to prefecture-level city, the number of networks and network density has dropped drastically. In 2018, the difference in quantity grows larger, during which the number of networks dropped from the previous 93 to 19 , a decrease of $79.57 \%$. The Greater variation also exist between the prefecture-level city to the county-level city and the prefecture-level city to the county level. 2) The number of networks from county-level cities to prefecture-level cities is only 1 , the number at county-level cities to counties and cities is 0 , indicating that limitation of provincial-level boundaries plays an important role when new branches set up from county-level cities. It is also related to the strength and scale of the bank who sets up its headquarters in the county-level city. It is highly consistent with the theoretical analysis above that, the financial industry within the financial growth pole has a gap in the level, scale and intensity of the financial function compared to the financial center, so the radiation it can produce is limited.

Table 1. The global density of financial resources flow network between financial gradation cities in the Yangtze River Delta.

\begin{tabular}{lllllll}
\hline \multirow{2}{*}{ year } & \multicolumn{2}{l}{ prefecture-level city } & \multicolumn{2}{l}{ country-level city } & country & \\
\cline { 2 - 7 } & network & density & network & density & network & density \\
\hline 2010 & 46 & 0.077 & 54 & 0.053 & 29 & 0.023 \\
2014 & 56 & 0.093 & 86 & 0.084 & 52 & 0.042 \\
2018 & 93 & 0.155 & 114 & 0.111 & 76 & 0.061 \\
2010 & 6 & 0.006 & 3 & 0.002 & 2 & 0.001 \\
2014 & 13 & 0.013 & 11 & 0.007 & 5 & 0.002 \\
2018 & 17 & 0.017 & 16 & 0.010 & 10 & 0.005 \\
\hline
\end{tabular}

Table 2. The density of trans-provincial financial resources flow network between financial gradation cities in the Yangtze River Delta.

\begin{tabular}{lllllll}
\hline \multirow{2}{*}{ year } & \multicolumn{2}{l}{ prefecture-level city } & \multicolumn{2}{l}{ country-level city } & country \\
\cline { 2 - 7 } & network & density & network & density & network & density \\
\hline 2010 & 13 & 0.022 & 3 & 0.003 & 1 & 0.001 \\
2014 & 17 & 0.028 & 14 & 0.014 & 2 & 0.002 \\
2018 & 19 & 0.032 & 15 & 0.016 & 2 & 0.002 \\
2010 & 1 & 0.001 & 0 & 0.000 & 0 & 0.000 \\
2014 & 1 & 0.001 & 0 & 0.000 & 0 & 0.000 \\
2018 & 1 & 0.001 & 0 & 0.000 & 0 & 0.000 \\
\hline
\end{tabular}

Table 3. The density of trans-city financial resources flow network between financial gradation cities in the Yangtze River Delta.

\begin{tabular}{lllllll}
\hline \multirow{2}{*}{ year } & \multicolumn{2}{l}{ prefecture-level city } & \multicolumn{2}{l}{ country-level city } & country \\
\cline { 2 - 6 } & network & density & network & density & network & density \\
\hline 2010 & 46 & 0.077 & 41 & 0.040 & 18 & 0.014 \\
2014 & 56 & 0.093 & 72 & 0.070 & 41 & 0.033 \\
2018 & 93 & 0.155 & 100 & 0.098 & 65 & 0.052 \\
2010 & 4 & 0.004 & 1 & 0.001 & 0 & 0.000 \\
2014 & 11 & 0.011 & 7 & 0.004 & 2 & 0.001 \\
2018 & 12 & 0.012 & 12 & 0.007 & 7 & 0.003 \\
\hline
\end{tabular}

This paper studies the expansion of city commercial banks in different areas. It should be noted that, there is a general situation where a large number of commercial banks whose headquarters was located in urban areas of prefecture-level cities set up branches in the lower level cities or countries within the same prefecture-level city. In order to eliminate those influential factors, we strip out data of this kind, and the results obtained are shown in Table 3. E.g., in 2014, the number of networks (branches) from prefecture-level to county-level cities decreased from 114 to 100 , and the number of networks from prefecture-level to county level declined from 76 to 65 , indicating that $87.72 \%$ and $85.53 \%$ of the branches of commercial banks in prefecture-level cities are set up in country-level cities and counties respectively outside the home city.

The conclusions of our analysis are as following: First, the number of number of networks and the density of networks in all financial gradation cities in the Yangtze River Delta is increasing over time, indicating that the financial integration of the Yangtze River Delta has shown a steady trend of development. Second, in 2018, the financial resources replacement between the prefecture-level cities were the most frequent, and the density of the mobile network was the largest. It shows that the financial resources transfer and replacement between the central cities of the Yangtze River Delta is the 
strongest; Furthermore, financial resources flows and the density of the mobile network from the county-level cities to the prefecture-level central cities ranks second, indicating the financial growths has a strong reflow effect towards financial centers of the Yangtze River Delta. It also shows that the financial centers of the Yangtze River Delta has a greater appeal to their financial hinterlands, and the polarization effect is obvious. There is relatively few financial resources flow from the prefecture-level city has to the county, which shows that the financial effect of the Yangtze River Delta financial center on the financial hinterlands such as financial growth poles and financial fulcrums (diffusion effect) is limited. Third, the administrative boundary effect has a relatively significant impact on the flow of financial resources in the Yangtze River Delta, in which provincial administrative boundary effect is greater than municipal administrative boundary effect.

\subsection{Path Selection Analysis of Financial Resource Flows}

\subsubsection{Indicator Selection and Data Description}

According to the previous theoretical analysis, following indicators were selected to reflect various factors affecting the flow of financial resources: per capita GDP is used to measure the economic level of each city; The impact of globalization is measured by the level of import and export and the level of foreign capital utilization. the discrepancy in financial resources between regions is the most direct contributor for financial resources flows, therefore, two indicators, per capita deposits and loans and Financial Interrelations Ratio (FIR, the ratio between year-end loan amount and GDP) were used to reflect the level of regional financial development. Montiel et al found In the 1990s that foreign direct investment (FDI) played a significant role in the flow of finance in Asia [34], so this paper selects the actual use of foreign capital to characterize the impact of globalization. The Yangtze River Delta region is an export-oriented active market economy with a large number of export-oriented enterprises and sizeable non-public economy, and to measure the level of marketization, we select the total import and export volume of each city as an indicator. From the previous analysis, we can see that administrative boundaries have a certain impact on the flow of financial resources in the Yangtze River Delta. We introduce dummy variables 0 and 1 ( 1 means that both cities belong to the same Province, 0 means different provinces) to measure the role of provincial administrative boundaries.

Considering that the operating cycle of city commercial banks is throughout the year, the data of the bank branches selected in this paper is to the end of 2018, while the independent variable data is one-year lag to the end of 2017, and comes from the 2017 Shanghai Statistical Yearbook, Jiangsu Statistical Yearbook and Zhejiang Statistical Yearbook.

\subsubsection{Empirical Research Results}

The foregoing paper only analyzes the flow between different levels of cities from the perspective of geographical boundaries. However, in addition to the boundary factors, there are other factors have an impact on the flow of inter-city financial resources. Therefore, we take these factors into consideration by conducting our analysis of resources flows from prefecture-level cities to prefecture-level cities, and prefecture-level cities to county level cities. The QAP correlation analysis and QAP regression analysis are performed on the matrix of financial flow and the matrix of difference value in independent variables. The results are shown in Table 4.

Table 4. An analysis on city commercial banks' expansion path between financial gradation cities in the Yangtze River Delta.

\begin{tabular}{|c|c|c|c|c|c|c|c|c|c|}
\hline \multirow{3}{*}{$\begin{array}{l}\text { independent } \\
\text { variable }\end{array}$} & \multirow{3}{*}{ details } & \multicolumn{4}{|c|}{ prefecture-level city $\rightarrow$ prefecture-level city } & \multicolumn{4}{|c|}{ prefecture-level city $\rightarrow$ country-level city } \\
\hline & & \multicolumn{2}{|c|}{ QAP correlation analysis } & \multicolumn{2}{|c|}{ QAP regression } & \multicolumn{2}{|c|}{ QAP correlation analysis } & \multicolumn{2}{|c|}{ QAP regression } \\
\hline & & $\begin{array}{l}\text { correlation } \\
\text { coefficient }\end{array}$ & Prob & std & Prob & $\begin{array}{l}\text { correlation } \\
\text { coefficient }\end{array}$ & Prob & Std & Prob \\
\hline \multirow{3}{*}{$\begin{array}{l}\text { Level of financial } \\
\text { development }\end{array}$} & constant & & & 0 & & & & 0 & \\
\hline & $\begin{array}{l}\text { difference net of loan and deposit } \\
\text { amount per capita }\end{array}$ & -0.083 & 0.192 & -0.163 & 0.151 & 0.021 & 0.405 & $0.262 *$ & 0.066 \\
\hline & difference net of FIR & -0.042 & 0.330 & 0.15 & 0.157 & -0.079 & 0.225 & -0.067 & 0.291 \\
\hline $\begin{array}{l}\text { Level of } \\
\text { Marketization }\end{array}$ & $\begin{array}{l}\text { difference net of total imports and } \\
\text { exports }\end{array}$ & -0.084 & 0.142 & -0.061 & 0.275 & $-0.125 *$ & 0.052 & $-0.143 *$ & 0.088 \\
\hline $\begin{array}{l}\text { Level of economic } \\
\text { development }\end{array}$ & difference net of GDP per capita & -0.071 & 0.247 & 0.074 & 0.301 & -0.095 & 0.147 & $-0.234^{*}$ & 0.069 \\
\hline \multirow[t]{2}{*}{ Level of integration } & $\begin{array}{l}\text { administrative boundaries } 0-1 \\
\text { network }\end{array}$ & 0.017 & 0.374 & 0.024 & 0.341 & $0.125^{*}$ & 0.058 & $0.140 * *$ & 0.041 \\
\hline & adjusted $\mathrm{R}^{2}$ & & & 0.012 & & 0.005 & & 0.056 & \\
\hline
\end{tabular}

Note: $* * * * * *$ respectively indicate that the results have passed the significance test at $1 \%, 5 \%$ and $10 \%$.

In general, the determination coefficient of QAP regression analysis is generally lower than that of the OLS regression analysis of the same data [32]. The prefecture-level city-prefecture-level city model can explain the $1.2 \%$ variation of the financial mobility network, while the prefecture-level city-city model can explain the 5.6\%. It can also be seen that the influencing factors of the financial flow between different city types are inconsistent. In the flow 
between prefecture-level cities, the previous main factors are not significant except for the use of foreign capital that is at the $10 \%$ level of significance. This is because the overall level of development in the 16 central cities of the Yangtze River Delta is relatively homogeneous with better economic and financial situation and more frequent financial resources flow, and therefore the density of financial network and the degree of integration between cities is higher. This implies that in the Yangtze River Delta urban agglomeration, the flow and diffusion of financial resources between financial centers presents the feature of even spread, which means that there is no obvious spatial preference for the expansion of financial institutions between cities. On the contrary, when referring to the flow from prefecture-level cities to counties and cities, the flow of financial resources will be limited by various factors, among which the greatest factor is administrative boundary. For example, whether they are in the same province, that is, the resources flow from prefecture-level cities to the county-level city will be significantly affected by the boundary effect of the province. Ji Feifei et al. found that the expansion of financial institutions between prefecture-level cities was significant without subdividing the 16 provincial-level city in Yangzi-river Delta into certain gradation when conducting similar research [15]. However, the conclusion is inconsistent compare to our research. We find that the boundary effects is not significant for the expansion between prefecture-level cities and only significant for the expansion from prefecture-level cities to country level cities or countries. It suggests that the efforts made by governments to eliminate the administrative boundary limitation in the financial integration process of the Yangtze River Delta should be more targeted, stressing on widening the financial channels from prefecture-level cities to counties and cities. Policies such as the current regional financial coordination policy and regional credit system construction should be implemented into counties and cities levels to eliminate administrative boundary limitation, realize the barrier-free flow of financial resources between nodes and achieve financial integration in Yangzi River Delta. Secondly, differences in levels of economic development, financial development and opening up between prefecture-level cities and country-level cities and countries will affect the choice in expansion of financial institutions. This indicates that the expansion of financial institutions in the Yangtze River Delta from the financial center to the financial hinterland is characterized by conditional diffusion. The foremost reason is that, the commercial banks are enterprises in essence whose economic activities cannot deviate from the pursuit of profits, and the expansion of which will be considered in terms of both cost and benefit. Under the risk of information asymmetry, only when they have total confidence in low entry costs and stable income, such as stable deposits and loans, will they input their capitals. Therefore, all governments and enterprises in country level cities and countries should also optimize the economic and financial environment, and strive to narrow the gap between the prefecture-level cities to reach the financial radiation of prefecture-level cities and gain more development of local economy, as an old Chinese saying goes, planting the phoenix tree before attracting the golden phoenix.

\section{Analysis of Discrepancies in Financial Resources Inflows in Different Financial Gradation Cities}

In preceding part of the paper, we analysis the flow of financial resources between different financial gradation cities. As can be seen from Table 1, financial inflows of financial fulcrum and financial growth pole are more from the radiation of financial centers, while the financial resources inflow of financial center are more of the resources flow circulation and replacement with the same gradation cities. In terms of the number of inflow institutions, the former is larger than the latter, but since the number of cities in financial hinterland is far larger than the number of financial center cities, the latter has a greater inflow density. These conclusions merely arise from an analysis of different types of financial gradation cities as a whole; we haven't dug into the difference in the degree of resource inflow between these cities. The following research will look into the degree of internal inflow difference between different financial gradation cities using the Dagum decomposition method. A commercial bank may set up new branches either in a unfamiliar place where it never had branch before or in a familiar place where there is already one or more branches. For the above situation, we come up with two ways to cope with the difference and shows the results respectively in Table 5 and Table 6 . In Table 5, the effect of branches numbers is under no consideration, thus the places where the banks have already had one or more branches, were assigned the value of 1 , otherwise, were assigned the value of 0 . In addition, in Table 6, we take the number of branches that has set up in the destination city into consideration.

Firstly, we used Dagum decomposition method to analyze the degree of difference about financial resources in different city levels. In addition, when setting up new branches, financial institutions may set up the branches in a city with no former branches, or they may add up a new one in cities with existing branches of their own company. For these two cases, this paper analyzes separately, as shown in Table 5. Regardless of the number of institutions, no matter how many are opened, they are taken as 1 , otherwise they are 0 , while Table 6 considers the number of institutions.

1) It can be seen that during the observation period, the difference in indegree (the number of institutions flowing in) of the overall Yangtze River Delta urban agglomeration is quite high, but it is steadily decreasing year by year, which suggests that the regional disparity is decreasing. This is because as time pass by, more and more branches are set up, making cities with no institutions fewer and fewer, and therefore leads to a lower degree of the overall discrepancies, which suggest a higher degree of financial integration. In 2010-2018, the overall degree of difference decreased by $4.2 \%$ annually. 
2) What's more, the degree of difference is also declining within different financial gradation: the largest decline is in prefecture-level cities, with an average annual decline of $9.3 \%$, indicating that the difference in financial resources inflows between prefecture-level cities has narrowed and reached an equilibrium in some cases. This finding is accord with previous analysis that the flow of financial resources between prefecture-level cities has reached a homogeneous diffusion. The average degree of variance ranked highest within country-level cities due to their differences in capability to attract financial resources and ranked lowest within countries because a generally lack of financial resources. In addition, through the original data, it is found that in some county-level cities with better economic conditions, such as Cixi, Wenling and Yuyao, large number of financial institutions were attracted to set up new branches. At the end of 2018, there were 36, 41 and 28 branches respectively, but there are also some county-level cities exist even none, the number of new branches was 0 in nine country-level cities such as Qingyuan, Donghai and Binhai.

3) In accord with the overall situation, the difference in the degree of financial resource inflow between different levels of cities is also steadily decreasing. The difference between prefecture-level cities and county-level cities is the largest, followed by prefecture-level cities and counties, and county-level cities and countries.

4) When considering the number of branches flowing into financial institutions, the difference in financial resource inflows between cities in the Yangtze River Delta increased. The average Gini coefficient during the inspection period was as high as 0.715 showing an increase of $68.4 \%$ on the previous basis, and within the hierarchy or between the levels, the degree of difference between cities is significantly greater. This shows that a Matthew effect exist in the inflow of financial resources in various cities, that is, cities with better economic and financial environment will be more attractive to financial institutions when setting up new branches. This can be explained from the perspective of the cost-effectiveness of bank expansion: on the one hand, regions with no financial institution generally lies in poor economic and financial environment and may lead to profit uncertainty. Therefore, banks tend to set up branches in areas with relatively good economic and financial environment that can create stable income. On the other hand, the expansion of branches shape scale benefit, and because they have already set up branches in the destination area, they get more familiar with them, so the risk of information asymmetry when setting up new branches in these regions is relatively low, and the entry cost is lower. This situation is particularly evident in prefecture-level cities and counties. The Gini coefficient within prefecture-level cities increased by $68.79 \%$ if consider the number of branches, followed by county-level cities, which increased by $52.21 \%$. It can be seen that the inflow of financial resources in cities and counties has a tendency of Matthew effect.

Table 5. The degree of difference and its decomposition without considering the number of financial institutions.

\begin{tabular}{|c|c|c|c|c|}
\hline \multirow{2}{*}{ Year } & \multirow{2}{*}{ Overall } & \multicolumn{3}{|l|}{ Intra-hierarchy gap } \\
\hline & & Prefecture-level city & Country-level city & country \\
\hline 2010 & 0.499 & 0.365 & 0.409 & 0.562 \\
\hline 2014 & 0.420 & 0.251 & 0.374 & 0.375 \\
\hline 2018 & 0.354 & 0.167 & 0.308 & 0.406 \\
\hline mean & 0.424 & 0.261 & 0.364 & 0.448 \\
\hline Average annual growth & -0.042 & -0.093 & -0.035 & -0.040 \\
\hline
\end{tabular}

Table 5. Continued.

\begin{tabular}{|c|c|c|c|c|c|c|}
\hline \multirow[b]{2}{*}{ Year } & \multicolumn{3}{|l|}{ Inter-hierarchy gap } & \multicolumn{3}{|c|}{ Contribution rate (\%) } \\
\hline & $\begin{array}{l}\text { prefecture-level } \\
\text { city-country-level city }\end{array}$ & $\begin{array}{l}\text { prefecture-level } \\
\text { city-country }\end{array}$ & $\begin{array}{l}\text { country-level } \\
\text { city-country }\end{array}$ & $\begin{array}{l}\text { Intra-hierarchy } \\
\text { gap }\end{array}$ & $\begin{array}{l}\text { Inter-hierarchy } \\
\text { gap }\end{array}$ & $\begin{array}{l}\text { intensity of } \\
\text { transvariation }\end{array}$ \\
\hline 2010 & 0.437 & 0.601 & 0.526 & 28.340 & 52.244 & 19.416 \\
\hline 2014 & 0.375 & 0.542 & 0.451 & 26.109 & 57.824 & 16.067 \\
\hline 2018 & 0.283 & 0.432 & 0.394 & 29.368 & 51.273 & 19.359 \\
\hline mean & 0.365 & 0.525 & 0.457 & 27.939 & 53.780 & 18.281 \\
\hline Average annual growth & -0.053 & -0.040 & -0.036 & 0.004 & -0.002 & -0.000 \\
\hline
\end{tabular}

Table 6. The degree of difference and its decomposition in terms of the number of financial institutions.

\begin{tabular}{|c|c|c|c|c|}
\hline \multirow{2}{*}{ Year } & \multirow{2}{*}{ Overall } & \multicolumn{3}{|l|}{ Intra-hierarch gap } \\
\hline & & prefecture-level city & country-level city & country \\
\hline 2010 & 0.782 & 0.542 & 0.567 & 0.614 \\
\hline 2014 & 0.705 & 0.433 & 0.557 & 0.508 \\
\hline 2018 & 0.657 & 0.346 & 0.536 & 0.517 \\
\hline mean & 0.715 & 0.440 & 0.553 & 0.546 \\
\hline Average annual growth & -0.021 & -0.055 & -0.007 & -0.021 \\
\hline
\end{tabular}


Table 6. Continued.

\begin{tabular}{|c|c|c|c|c|c|c|}
\hline \multirow[b]{2}{*}{ Year } & \multicolumn{3}{|l|}{ Inter-hierarchy gap } & \multicolumn{3}{|c|}{ Contribution rate $(\%)$} \\
\hline & $\begin{array}{l}\text { prefecture-level city- } \\
\text { country-level city }\end{array}$ & $\begin{array}{l}\text { Prefecture-level } \\
\text { city-country }\end{array}$ & $\begin{array}{l}\text { Country-level city } \\
\text {-country }\end{array}$ & $\begin{array}{l}\text { Intra- } \\
\text { hierarchy gap }\end{array}$ & $\begin{array}{l}\text { Inter-hierarchy } \\
\text { gap }\end{array}$ & $\begin{array}{l}\text { Intensity of } \\
\text { transvariation }\end{array}$ \\
\hline 2010 & 0.827 & 0.929 & 0.681 & 17.776 & 77.745 & 4.478 \\
\hline 2014 & 0.721 & 0.891 & 0.660 & 17.826 & 78.154 & 4.020 \\
\hline 2018 & 0.675 & 0.853 & 0.616 & 17.709 & 77.782 & 4.508 \\
\hline mean & 0.741 & 0.891 & 0.652 & 17.770 & 77.894 & 4.336 \\
\hline Average annual growth & -0.025 & -0.011 & -0.012 & 0.000 & 0.000 & 0.001 \\
\hline
\end{tabular}

\section{Conclusions}

This paper constructs the urban financial resource flow network base on the expansion of urban commercial banks, and draws upon the theory of financial resources flow in financial gradation cities in urban agglomeration. Social network analysis tools and The Dagum method were used to studies the flow density, flow path, and flow coordination of financial resources in various cities in the Yangze river delta in 2010-2018 from perspectives of prefecture-level cities, county-level cities and counties, and some meaningful conclusions and inspirations were obtained.

(1) Although the flow density among central cities is high, the diffusion effect they create is insufficient. By measuring the network density with the Social Network Analysis method to calculate the flow density between different financial cities, it is found that as time goes by, the financial resources flow in the Yangtze River delta measured by urban geographical expansion of commercial banks keeps increasing. The flow among prefecture-level cities has the highest density, followed by county-level cities to prefecture-level cities, while the network density of prefecture-level cities to country level cities and countries is relatively low. This indicates that the spatial interaction characteristics of the cities in the Yangtze River Delta urban agglomeration mainly characterized by the flow among the financial centers and its agglomeration effect on financial growth poles, while the central cities themselves has insufficient diffusion effect on its financial hinterland, which remains to be improved.

(2) The path choice of resources flow between different financial gradation cities are quite different. The QAP regression analysis method is used to analyze the influencing factors of path choice of resources flow among different cities. It is found that the discrepancies of economic and financial environment among prefecture-level cities have a relatively small impact. In addition, when taking the influence of administrative boundary into consideration, although the flow density between various types of gradation cities has somewhat decreased, the provincial administrative boundaries have no significant impact on the flow of financial resources between prefecture-level cities. It can be inferred that the integration of financial resources between the prefecture-level cities in the Yangtze River Delta is relatively high, and the flow of financial resources between cities is relatively smooth. It also indicates that the flow and diffusion of financial resources among central cities in the Yangtze River Delta urban agglomerations exhibits a characteristic of uniform diffusion - that is, the expansion of financial institutions has no obvious spatial orientation. However, things changed when the prefecture-level cities based financial institutions seek to expand country-level cities or country. That is to say, more factors are taken into consideration by the decision-makers, among which the most significant factor is whether the country-level cities or country are in the same province as the headquarters, followed by the degree of differences in economic and financial development levels, and the level of opening up to the outside world. These factors will affect the inflow of financial resources from prefecture-level cities into their financial hinterland, as well as the influence of their financial radiation effect on country-level cities and countries. It suggest that a conditional diffusion effect exist in the expansion of financial institutions in the Yangtze River Delta from the financial centers (prefecture-level cities) to their financial hinterlands. Therefore, on the one hand, the provincial government should put more emphasis on the construction of macro-level integration, for example, regional financial coordination of the whole region should be improved and the country-level cities and countries should be engaged into the construction of regional credit system. On the other hand, local governments, especially those at the county-level cities and countries, should optimize the local financial environment and make full use of the radiation effects from financial centers on its financial hinterlands.

(3) The inflow of financial resources is inconsistent among the financial gradation cities, and there is a tendency of Matthew effect. Indegree is ued to measure the degree of financial resources inflow, and the Dagum decomposition model is used to decompose the differences in the inflow of financial resources of various types of cities. It is found that the degree of difference within the county-level cities is the highest, followed by the prefecture-level cities and countries. By looking over the original data, it can be seen that there are large discrepancies in the financial and economic environment of the county-level cities in the Yangtze River Delta - In some county-level cities with good financial and economic conditions, such as Cixi City and Wenling City, a large number of financial institutions were attracted, while there are also 7 county-level cities that have not attracted even one branch. When considering the repeated opening of branches of financial institutions, the degree of difference is significantly greater, among which prefecture-level cities increase most, followed by counties, which increase by $68.79 \%$ and $52.27 \%$ respectively. It can be seen that the inflow of financial resources has a tendency of "Matthew effect", and the decision-makers in the Yangtze River Delta have insufficient 
coordination to cope with the current financial environment differences between counties and cities, which is not conducive to the coordinated development of the Yangtze River Delta financial economy. At the same time, local governments, especially government of those cities or countries with less financial institutions inflows, should put more effort improve local economic and financial environment. On the other hand, it is necessary to offer financial institutions with preferential policy, putting fully consideration of the interests of city commercial banks.

The flow of financial resources is a rather complicated process. The shortcoming of this paper is that it only examines the special situation of urban commercial banks' expansion without involving other financial resources, such as monetary funds and financial systems.

\section{References}

[1] Wei Qing. Research on the Flow of Financial Resources and Financial Integration in the Yangtze River Delta. Beijing: China Commercial Publishing House, 2011.

[2] Brouwer G D. Financial Integration in East Asia. Cambridge, UK: Cambridge University Press, 1999.

[3] Flood R P, Rose A K. Uncovered interest parity in crisis. IMF Staff Papers, 2002: 49 (2): 252-266.

[4] Cheung Y W, Chinn M D, Fujii E. The Chinese economies in global context: The integration process and its determinants. Journal of the Japanese and International Economies, 2006, 20 (1): $128-153$

[5] Akram Q F, Rime D, Sarno L. Does the law of one price hold in international financial markets? Evidence from tick data. Journal of Banking \& Finance, 2009, 33(10): 1741-1754.

[6] Yu I W, Fung K P, Tam C S. Assessing financial market integration in Asia- equity markets. Journal of Banking \& Finance, 2010, 34 (12): 2874-2885.

[7] Feldstein M, Horioka C. Domestic saving and international capital flows. Economic Journal, 1980, 90 (6): 314-329.

[8] Le H G. Financial openness and financial integration. In: Asia Pacific School of Economics and Management Working Paper, 2000: 1-4.

[9] Isaksson A. Financial liberalisation, foreign aid and capital mobility: Evidence from 90 developing countries. Journal of International Financial Markets, Institutions and Money, 2001, 11 (3): 309-338.

[10] Kim H, Oh K Y, Jeong C W. Panel cointegration results on international capital mobility in Asian economies. Journal of International Money and Finance, 2005, 24 (1): 71-82.

[11] Guillaumin C. Financial integration in East Asia: Evidence from panel unit root and panel co-integration tests. Journal of Asian Econoics, 2009, 20 (3): 314-326.

[12] Hou Yunhui, Liu Hong. Quantitative analysis to the city agglomeration structure based on social network: A case of capital exchange network of the Yangtze River Delta. Complex System and Complexity Science, 2006, 2 (6): 35-42.
[13] $\mathrm{Hu} \mathrm{Kai}$, An empirical study on the scale of interprovincial capital mobility in China. Economic Geography, 2011, 31 (1): 90-96.

[14] Bai Qinxian, Ding Zhijie. Discuss the Sustainable development of Finance. Studies of International Finance, 1998, (5): 28-32.

[15] Ji Feifei, Chen Wen. Distribution pattern and expansion mechanism of financial institution network in the Yangtze River Delta. Progress in Geography, 2014, 33 (9): 1241-1251.

[16] Bagler G. Analysis of the airport network of India as a complex weighted network. Physica A, 2008, 387 (12): 2972-2980.

[17] Ter Wal A L J, Boschma R A. Applying social network analysis in economic geography: Framing some key analytic issues. The Annals of Regional Science, 2009, 43 (3): 739-756.

[18] Li Xiang. Research on the Yangtze River Delta urban agglomeration network structure based on social network analysis. Urban Studies, 2011, 18 (12): 80-85.

[19] Zhen Feng, Wang Bo, Chen Yingxue. China's city network characteristics based on social network space: An empirical analysis of sina micro-blog. Acta Geographica Sinica, 2012, 67 (8): 1031-1043.

[20] Wang Yu, Chen Wen, Yuan Feng. Human mobility and evolution based on social network: An empirical analysis of Yangtze River Delta. Geographical Research, 2014, 33 (2): 385-400.

[21] Gu Chaolin, Pang Haifeng. Study on spatial relations of Chinese urban system: Gravity model approach. Geographical Research, 2008, 27 (1): 1-12.

[22] Leng Bingrong, Yang Yongchun, Li Yingjie, et al. Spatial characteristics and complex analysis: A perspective from basic activities of urban networks in China. Acta Geographica Sinica, 2011, 66 (2): 199-211.

[23] Zhang Fengchao. The Research of Financial Area System: An Explanation about Financial Integration. Beijing: People's Publishing House, 2006.

[24] Lin Yifu, Sun Xifang, Jiang Ye. Toward A theory of optimal financial structure in economic development. Economic Research Journal, 2009, (8): 4-17.

[25] Haggett P, Chorley R J. Network Analysis in Geography. London: Edward Arnold, 1969.

[26] Ullman E L. Human geography and area research. Annals of the Association of American Geographers, 1953, 43 (1): 54-66.

[27] Hagestrand T. Innovation as A Spatial Process. Chicago: Chicago University of Press, 1967.

[28] Lu Jun. Spatial Movement of External Part of City and Regional Economy. Beijing: China City Press, 2011.

[29] Ji Feifei, Chen Wen, Wei Yehua, et al. Changing financial flow patterns and driving mechanisms of financial flows under the integration of the Yangtze River Delta: An analysis of the financial transaction data of listed companies. Acta Geographical Sinica, 2014, 69 (6): 823-837.

[30] Li Xiaojian. Spatial system of urban agglomeration in district development. Economic Geography, 2006, 26 (5): 721-725.

[31] Zhou L, Hu Angang. Differences of regional financial development disparity in China (1978-1999). Journal of Tsinghua University: Philosophy and Social Sciences, 2002, 17 (2): 60-74. 
[32] Liu Jun. Lectures on whole network approach: A Practical Guide to UCINET. Shanghai: Truth and Wisdom Press, 2009.

[33] Dagum C. A New approach to the decomposition of the Gini income inequality ratio. Empirical Economics, 1997, 22 (4): 515-531.
[34] Montiel P, Reinhart C M. Do capital controls and macroeconomic policies influence the volume and composition of capital flows? Evidence from the 1990s. Journal of International Money and Finance, 1999, 18 (4): 619-635. 